\title{
A Study on the Cultivation of CAT Ability of Translation Majors in Big Data Era
}

\author{
Wang Jing \\ Department of translation, College of foreign languages \\ Zhejiang International Studies University \\ Hangzhou, China
}

\author{
Zhu Xiaodong \\ Information Institute \\ Ningbo City College of Vocation Technology \\ Ningbo, China \\ zxdningbo@126.com
}

\begin{abstract}
This paper discusses how to improve the ability of college students majoring in translation to use CAT software. With the arrival of big data's time, the mode of translation has also changed greatly. For example, the new mode based on "Internet big data Translation", represented by crowdsourcing translation, has become an embryonic form. Every translator can cooperate with all kinds of translators around the world through the translation platform. In order to adapt to this kind of work mode, the translator must have the ability to make use of all kinds of information technology and tools. The most important of these tools is the CAT (computer aided Translation) software. Only when students are able to skillfully use a variety of tools, including using a cloud translation (machine translation) platform, can they adapt to the requirements of the current language service market for translators who will be more competitive in the future job market.
\end{abstract}

Keywords-Internet +; Big data; Crowdsourcing translation; Computer aided translation; Machine translation

\section{INTRODUCTION}

With the popularization of the technology of mobile Internet, large data and cloud computing, the revolution of information technology is bringing great impact and influence to the traditional industries. The model of translation work based on 'Internet, big data and translation", represented by "Crowdsourcing Translation ", has become a prototype. The translation work is no longer the use of limited personal resources for creation, but the use of large amounts of large data on the Internet to cooperate with various translators all over the world through the translation platform. If anyone can make good use of information technology and "Internet + big data + translation" platform, he will have a better development prospect and opportunity. The traditional mode of translation mainly originates from the enterprise and the publishing industry, the current "Internet +" model has begun to break the traditional boundaries of the translation industry, with the development of globalization, various aspects of the demand for translation has been a great release.

The research group (PACTE) of the American 'translation competence acquisition and evaluation" has proposed the structure model of translation ability in the last century, but there've been relatively few research achievements in English and Chinese computer aided translation so far. The research on computer-aided translation in Chinese and English is mainly

This study was supported by the education science planning project of Zhejiang province in 2018: "Research on CAT ability training for college translation students in large data age", No: 2018SCG379. carried out by Chinese scholars whose research is relatively late compared with foreign their counterparts. Because Chinese researches in this field are still in the initial stage, most of the studies are just the reflections on the translation teaching content for the development of translation technology. It is still insufficient for the study of taking translation technology as teaching content. Because CAT technology involves more knowledge of science and engineering, and at present, it posed much difficulty for the university students of translation majors. In order to make the teaching of CAT technology possible, it is particularly important to improve students' information technology processing ability.

\section{RESEARCH CONTENT AND STEPS}

\section{A. Research content and object}

The study focuses on all three stages in the process of any translation project, namely, before translation, in the middle of translation and after translation. It attempts to illustrate the role of modern language technology played in every aspect of translation practice from the micro level, as shown in Fig. 1.

Language service needs oriented curriculum content must be targeted at the actual employment skills demand of enterprises. The overall framework of the course covers all aspects of language services from information technology to project management. The overall framework of the study is shown in Fig. 2.

Fig. 2 shows that the main objectives of the translator's technical ability training in the information age include five parts. Therefore, it can be divided into five steps to improve the students' skills.

\section{B. Improve computer skills}

Computer skill is the essential quality of modern translators. In information era, source materials of translation are written in various formats. So the translator has to master the conversion of them (for example, converting PDF format or image format to word format), translatable resource extraction (for example, extracting text in XML documents), terminology extraction, language processing (for example, using macros to remove noise in information sources). 


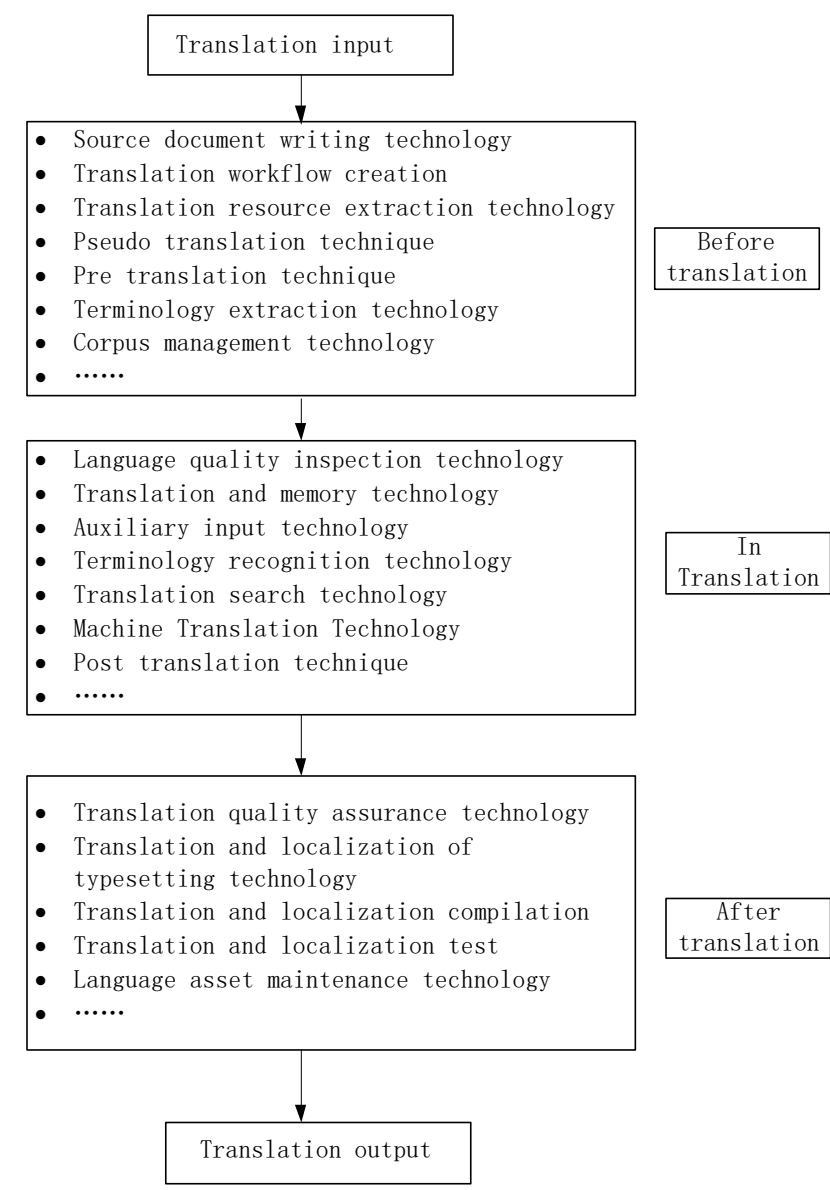

Fig. 1. Object of translation technology research

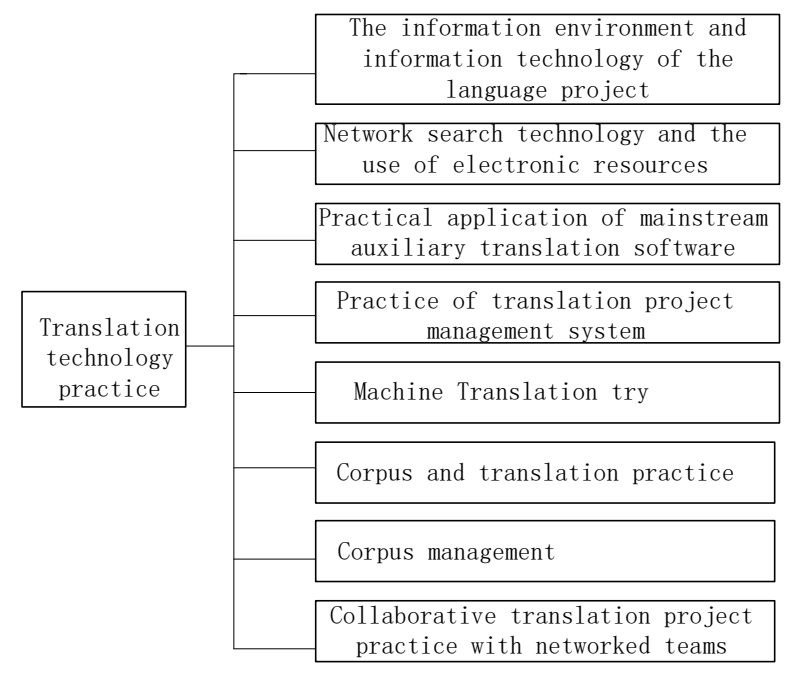

Fig. 2. General framework of translation technology

Translators should understand correctly the meaning of (TAG) markup in CAT tools, and be familiar with common web page code contents. Furthermore, it is better for the translator to learn simple programming such as Perl, Java, and Python, and master the language batch processing documents to compile, typeset and test the document after translation.
These basic skills will directly affect the speed of completing translation works, and the quality of them as well.

\section{Improving the ability of information retrieval}

With knowledge increasing at fast speed in the information age, new translation filed and professional terms are emerging. Therefore, translators must have good abilities of information retrieval, analysis, integration and reconstruction. Only when translators have a keen "search quotient" can they find the necessary information from the Internet within a limited time, and verify the correctness of the translation through a professional corpus. The translator should be familiar with mainstream search engines and the characteristics of corpus, and proficient in the selection of induced words, the use of retrieval grammar, and so on. In this way, the speed and accuracy of retrieval can be improved exponentially.

\section{Improving the ability to use cat tools}

In the information age, translation work is characterized by large workload, diverse translation tasks and timeliness. If the translation involves professional terms, it is more important to use modern CAT tools. According to the Survey of the Survival status of translators in China (2007), 61\% of the translators use CAT tools and $80 \%$ of them use online translation aids to some extent. According to the Global Free translator report of 2012, 65.3\% of translators are using CAT tools to improve translation efficiency. Jared's survey (2013) of professional translators of Proz website (Proz.com) shows that $88 \%$ translators use at least one CAT tool. At present, all the major language service companies are required to master the CAT or localization tools in addition to the traditional requirement of language competence, which shows that CAT tools are the necessary qualities of translators in the information age.

\section{E. Improving the ability to handle terminology}

Terminology processing ability refers to the knowledge and skill level needed to solve translation problems by using terminology theory and terminology tools. This kind of ability has the characteristics of compound and strong practicality, and it runs through the whole process of translation project, and it is one of the important professional abilities in the whole process of translating. Being an indispensable part of language service, term management ability is the core part of the translator's term competence. By using terminology management software, the translator can manage, maintain and update translation database, improve the quality, speed of translation and keep consistency of terms, and promote sharing of terminology information and knowledge. Therefore, translators in the information age need to grasp skills of systematic management of terms such as collecting, describing, processing, recording, storing, presenting and querying terminology.

\section{F. Improving the ability of post-translation editing}

Machine translation is a tool with great application potential in the language service industry, and it is gradually melting with CAT software. At present, almost all mainstream CAT software tools can be loaded with machine translation engine. The intelligent machine translation system can help the 
translator to reduce the workload. In this way translator's work mode has changed from manual translation to post-translation editing. A 2010 thematic survey of global language service by the Association of Automated users of Translation (IATS) shows that 49.3 per cent of suppliers regularly provide posttranslation editing services, 24.1 per cent have specially trained post-translational editors with the rest being distributed to freelance translators. Post-translation editing will become one of the necessary professional qualities for translators. The translators in the information age need to master the basic rules, strategies, methods, tools of and post-translation editing.

In the information age, university students of translation major should have abilities mentioned above. Abilities that should be improved urgently for them are mainly the first three. They are the foundation and with them other abilities can be quickly enhanced when doing specific translation tasks in the future.

\section{METHODS AND INNOVATIONS}

University students majoring in translation need not only foreign language knowledge, but also comprehensive translation technical skills. Traditional translation teaching is mainly around literary translation, emphasizing the translator's literary background, English reading comprehension and Chinese expressing ability. However, with the globalization and commercialization of language services in the information age, practical translation has become the main service business in the current language service market. Therefore, translators must be able to use all kinds of information technology and tools to ensure the quality of translation and improve the efficiency of translation. Thus apart from traditional translation ability, the important qualities of translators in the information age should include the excellent translation technical ability. Therefore, translation students must learn CAT technology and master many kinds of tools. The research on how to improve college translation students' comprehensive ability needs to be strengthened. These abilities include the ability to use the cloud translation (Machine Translation) platform, the ability to use machine aided translation software and the use of "large data+ Internet+ translation"service platform.

\section{A. Research method}

1) Data analysis: After using computer assisted instruction, teachers collect and analyze data of students' translation accuracy and speed. According to the analysis results, the classroom design and translation selection criteria are adjusted, and then tested. Continuous dynamic adjustment is conducted until the stability of the best results is achieved.

2) Case study: this study will be based on case analysis of translation accuracy of each student;

3) Questionnaire method: This study will design a questionnaire related to classroom teaching to help improve the classroom teaching effect.

\section{B. Academic and practical innovation}

This study attempts to make a breakthrough in academic ideas and viewpoints, changing the traditional teaching process is based on literary translation as the main research object, with the actual translation project as the main research object of teaching. As practical translation becomes the main service business of the current language service market, translators must be able to learn CAT technology and master a variety of tools with the help of various information technology and tools. Only when the translator has mastered these skills can he improve the efficiency of translation work while ensuring the quality of the translation.

This study attempts to organize translation teaching through authentic translation projects which will be provided to the students for intern tracking. University and the language service department of employer shall establish feedback mechanisms and assessment mechanism so as to achieve a positive interaction between school and enterprise in deep cooperation. Through the tracking and comprehensive evaluation of teaching process, enterprises should actively adjust their teaching orientation and constantly improve teaching contents and teaching methods. In this way, schools can cultivate professional, pluralistic highly qualified talents of language service for the society in line with the requirements of the times.

\section{Separation and ReORganization of Translation COURSES}

In order to improve the translation ability of translation majors it is necessary to split and reorganizing translation courses. Splitting and reorganizing the course of translation: In line with the characteristics of translation technology required by translation professionals in the information age, the curriculum is divided into five units, as shown in Table 1.

TABLE I. COMPOSITION OF THE TRANSLATION TECHNOLOGY COURSE

\begin{tabular}{|c|l|l|}
\hline & \multicolumn{1}{|c|}{ Unit name } & Mainly involved in the content \\
\hline 1 & $\begin{array}{l}\text { Information processing } \\
\text { capability }\end{array}$ & $\begin{array}{l}\text { Information search, format conversion, } \\
\text { data preprocessing, etc. }\end{array}$ \\
\hline 2 & $\begin{array}{l}\text { Computer aided software } \\
\text { practice }\end{array}$ & $\begin{array}{l}\text { Mainstream CAT tools reference, memory } \\
\text { library management, terminology } \\
\text { management }\end{array}$ \\
\hline 3 & $\begin{array}{l}\text { Post- translation editors } \\
\text { of machine translation }\end{array}$ & $\begin{array}{l}\text { Mainstream Machine Translation engine, } \\
\text { compilation process, cloud translation } \\
\text { technology }\end{array}$ \\
\hline 5 & $\begin{array}{l}\text { Localization technology } \\
\text { management }\end{array}$ & $\begin{array}{l}\text { Internationalization and localization, } \\
\text { localization process, commonly used } \\
\text { localization technologies and tools }\end{array}$ \\
\hline
\end{tabular}

The teaching reform of the separation and reconstruction of translation courses aims to achieve the following changes:

1) To change the teaching objectives: The traditional teaching aims are to enhance the ability of language transformation, and the goal of the reform is to enhance the technical ability of translation.

2) Changes in teaching content: the traditional teaching content generally takes literary works as an example to explain the translation skills. The teaching content after the reform is 
aimed at teaching translation skills and teaching translation tools at the same time.

3) The change of teaching methods:

The teaching methods of traditional translation are teachers' leading the role of explaining and students' practicing translation. After the reform, the way of teaching is to carry out practical translation exercises on the machine.

4) Project-driven job assessment: Teachers introduce authentic translation projects into the classroom, emphasizing the cultivation of students' cognitive ability and comprehensive translation ability in authentic translation project.

5) Data-driven comprehensive assessment: teachers can use the curriculum platform to conduct course assessment from aspects of curriculum setting, teaching plan preparation, teaching arrangement, homework evaluation, syllabus completion, student skills improvement index and adjust teaching according to the evaluation result.

\section{Summary AND PRospects}

When the translation technology of college translation students is improved, the translation efficiency will be improved. Compared with traditional manual translation, CAT has unparalleled advantages, which can significantly improve the translation quality and speed of translators. Human translation work limit is $\mathbf{5 0 0 0}$ words per day or so. But with the help of a CAT tool, skilled translators can easily achieve 10000 words per day. CAT technology can guarantee the accuracy of the translation, keep the consistency of terminology, and create more economic benefits. In this way, students' employment competitiveness will be improved.

\section{ACKNOWLEDGMENTS}

This study was supported by the education science planning project of Zhejiang province in 2018: "Research on CAT ability training for college translation students in large data age", No: 2018SCG379.

\section{REFERENCES}

[1] Boeker, L. Computer-Aided Translation Technology: A Practical Introduction[M]. Ottawa: University of Ottawa Press, 2002.

[2] Sin-wai, C. A Dictionary of Translation Technology[M]. Hong kong: Chinese University press, 2004.

[3] Sin-wai, C. The Routledge Encyclopedia of Translation Technology[C]. London: Routledge, 2015.

[4] Stephen Billett(2004) . From Your Business to Our Business: Industry and VocationalEducation in Australia, Oxford Review of Education, Vol. 30, No. 1, Special Issue: Business, Education and Vocationalis m (Mar., 2004), pp. 13-35.

[5] EMT. Competences for Professional Translators, Experts in Multilingual and Multimedia Communication[EB/OL]. Retrieved from http://ec.europa.eu/dgs/translation/programmes/emt/key documents/emt competences translators en.pdf, 2017-03-25.

[6] Jared. CAT Tool Use be Translators: Who Is Using?[EB/OL]. Retrieved from http://prozcomblog. com/2013/03/22/cat-tool-use-by-translatorswho-is-using, 2017-05-25.

[7] ProZ.com Members. State of the industry: Freelance translators in 2012[R]. ProZ.com, 2012.

[8] Munday J. Introducing Translation Studies: Theories and Applications (3rd ed.) [M]. London: Routledge,2012. 